\title{
Educação a distância, educação aberta e inclusáo - dos modelos transmissivos às práticas abertas
}

\section{Lúcia Amante}

Doutora em Ciências da Educação pela Universidade Aberta (UAb), Lisboa, Portugal. Docente na UAb e investigadora no Laboratório de Educação a Distância e Elearning (LE@D), Lisboa, Portugal.

E-mail: Lucia.Amante@uab.pt

\section{António Quintas-Mendes}

Doutor em Ciências da Educação pela Universidade Aberta (UAb), Lisboa, Portugal. Docente na UAb e investigador no Laboratório de Educação a Distância e Elearning (LE@D), Lisboa, Portugal.

E-mail: quintasmendes@gmail.com

Submetido em: 09/01/2018. Aprovado em: 31/01/2018. Publicado em: 04/04/2018.

\section{RESUMO}

Partindo do princípio de base da democratização do conhecimento e acesso ao saber, subjacente à educação a distância, procura-se neste texto situar a conceção de educação em geral e dos seus modelos, no contexto histórico, económico e social em que se desenvolvem, contrapondo as necessidades da sociedade industrial com as que emergem na atual sociedade em rede. Aborda-se depois o papel específico da educação a distância (EaD) e detém-se na evolução destes sistemas e dos seus modelos pedagógicos, decorrentes da inovação tecnológica, referindo em particular o caso da Universidade Aberta portuguesa (UAb). Em seguida abordase o conceito de educação aberta, que vai mais além que o de educação a distância e ao qual se associam conceitos e práticas como a dos recursos educacionais abertos (REA), práticas educacionais abertas (PEA) e ambientes pessoais de aprendizagem (APA), fundamentais no desenvolvimento e amadurecimento quer da EaD quer da Educação Aberta. A concluir, reflete-se sobre o papel que a EaD e as evoluções que lhe estão associadas poderão ter na mudança de um paradigma de ensino transmissivo para o desenvolvimento de contextos de aprendizagem que privilegiem práticas abertas, participadas e transformadoras. Práticas que propiciem o desenvolvimento de competências pertinentes para um mundo em constante mudança e que promovam, simultaneamente, a emancipação humana rumo a uma sociedade verdadeiramente aberta e inclusiva.

Palavras-chave: Educação a distância. Educação aberta. Recursos educacionais abertos. Práticas educacionais abertas. Ambientes pessoais de aprendizagem. 


\section{Distance education, open education and inclusion - from transmissive models to open practices}

\section{ABSTRACT}

Starting from the basic principle of the democratization of and access to knowledge, which underlies Distance Education and Open Education, we situate its theories and practices in the context of the economic, social and cultural changes that have been generated in the transition from industrial society to the digital and networked society. We then discuss the specific role of Distance Education (DE) and analyse the evolution of these systems and their pedagogical models, resulting from technological and pedagogical innovation, referring in particular to the case of the Portuguese Open University (UAb). We then approach the concept of Open Education (OE), which goes beyond the concept of Distance Education and which is associated with concepts and practices such as Open Educational Resources (OER), Open Educational Practices (OEP) and Personal Learning Environments (PLE), which are fundamental in the development and maturation of both Distance Education and Open Education. To conclude, we reflect on the role that Distance Education and its related developments may have on the change from a transmissive teaching paradigm to the development of learning contexts that provide open, participatory and transformative practices. Practices conducive to the development of relevant skills to a changing world while simultaneously promote human emancipation towards a truly open and inclusive society.

Keywords: Distance education. Open education. Open educational resources. Open educational practices. Personal learning environments.

\section{Educación a distancia, educación abierta e inclusión - de los modelos transmisivos a las prácticas abiertas}

\section{RESUMEN}

Partiendo del principio de base de la democratización del conocimiento y acceso al saber, subyacente a la Educación a Distancia, buscamos en este texto situar la concepción de Educación en general y de sus modelos, en el contexto histórico, económico y social en que se desarrollan, contraponiendo las necesidades de la sociedad industrial con las que emergen en la actual sociedad en red. Abordamos después el papel específico de la Educación a Distancia (EaD) y nos detenemos en la evolución de estos sistemas y de sus modelos pedagógicos, derivados de la innovación tecnológica, refiriéndose en particular el caso de la Universidad Abierta portuguesa (UAb). En seguida abordamos el concepto de Educación Abierta, que va más allá que el concepto de Educación a Distancia y al que se asocian conceptos y prácticas como la de los Recursos Educacionales Abiertos (REA), Prácticas Educacionales Abiertas (PEA) y Ambientes Personales de Aprendizaje (APA), fundamentales en el desarrollo y maduración tanto de la EaD como de la Educación Abierta. En conclusión, reflexionamos sobre el papel que la EaD y las evoluciones que le están asociadas pueden tener en el cambio de un paradigma de enseñanza transmisiva para el desarrollo de contextos de aprendizaje que proporcionan prácticas abiertas, participadas y transformadoras. Prácticas que propicien el desarrollo de competencias pertinentes para un mundo en constante cambio y que promuevan al mismo tiempo la emancipación humana hacia una sociedad verdaderamente abierta e inclusiva.

Palabras clave: Educación a distancia. Educación abierta. Recursos educativos Abiertos. Prácticas educativas abiertas. Ambientes personales de aprendizaje. 


\section{INTRODUÇÃO}

Falar de educação a distância $(\mathrm{EaD})$ remete-nos, inevitavelmente, para o seu princípio de base, a democratizaçáo do conhecimento e do acesso aos saberes da escola, necessários na sociedade contemporânea e requeridos como forma de inclusão social já que, em grande parte, esta modalidade educativa sempre visou chegar àqueles que, por condicionantes diversas, estavam excluídos dos sistemas de ensino presencial. Mas falar de $\mathrm{EaD}$ é também falar de educação em geral e da sua relaçáo com o contexto histórico, económico e social em que tem lugar. Assim, iniciamos este texto com breve abordagem ao contexto históricosocial em que nasce a escola de massas e à relação que se estabelece entre esta e as respostas requeridas pela sociedade industrial, bem diferentes das que a atual sociedade digital exige e a que os sistemas educativos, presos à lógica da uniformizaçáo do século XIX, têm dificuldade em dar resposta. Abordamos depois o papel específico da educação a distância, designadamente os fatores que determinaram a criação das universidades abertas, e detemo-nos na evolução dos sistemas de $\mathrm{EaD}$, referindo em particular o caso da Universidade Aberta portuguesa (UAb).

Damos conta da evoluçáo de um modelo convencional de $\mathrm{EaD}$ para um modelo pedagógico de base virtual decorrente da evoluçáo das tecnologias da informação e da comunicação, sublinhando como esta evolução determinou a emergência destes novos modelos, dando origem à nova geração de $\mathrm{EaD}$ e a alteraçóes do paradigma de aprendizagem até aí dominante. Abordamos depois o conceito de educação aberta, que vai mais além do que o conceito de $\mathrm{EaD}$ e que acompanha, mais uma vez, as inovações tecnológicas. Com efeito é a partir do surgimento da Web 2.0, das plataformas de código aberto com livre acesso e com as práticas de licenciamento aberto, que a educaçáo aberta online assume um novo protagonismo. A este conceito de educação aberta associam-se outros, como os recursos educacionais abertos (REA), as práticas educacionais abertas (PEA) e os ambientes pessoais de aprendizagem (APA), fundamentais no desenvolvimento e amadurecimento quer da $\mathrm{EaD}$ quer da educação aberta, conforme procuramos dar conta.

Por fim refletimos sobre o papel que a $\mathrm{EaD}$ e as evoluçóes que lhe estão associadas poderão ter na mudança de um paradigma de ensino transmissivo para o desenvolvimento de contextos diferentes de aprendizagem, dando lugar a práticas abertas, participadas e transformadoras, importantes numa sociedade em que o conhecimento passou a ser fator determinante para o desenvolvimento. Acreditamos que a $\mathrm{EaD}$ e a educação aberta poderão contribuir para a refundaçáo dos atuais modelos educacionais, alargando a desejável qualificação e inclusão dos mais variados públicos.

\section{DA REVOLUÇÃO INDUSTRIAL À REVOLUÇÃO DIGITAL}

Sabemos que atualmente, em grande parte, o grau e a possibilidade de desenvolvimento de uma sociedade já não se avaliam pelas suas riquezas naturais ou pelas suas capacidades de produçáo industrial. No mundo atual, o domínio das novas tecnologias da informação e da comunicação e o nível de conhecimento de que essa sociedade dispóe passaram a constituir fatores determinantes.

Sabemos também, pelo que a História nos diz, que às grandes mudanças tecnológicas se associam por norma grandes mudanças sociais. De facto, se pensarmos na Revoluçáo Industrial constatamos as profundas mudanças provocadas na sociedade, não só no desenvolvimento do processo produtivo, mas igualmente mudanças que ocorreram no plano ideológico e cultural. Estabeleceram-se novos tipos de relacionamento social, e é no contexto da revolução industrial que se assiste à criação da escola, tal como ainda hoje a conhecemos, tendo em vista responder às exigências do sistema produtivo. Nessa época os saberes técnico-práticos eram a principal porta de entrada da ascensão social e a escola, a escola de massas, surge nessa altura, desenvolvendo-se ao longo da segunda metade do século XIX (NÓVOA, 1998). 
É nesse período histórico que há necessidade de expandir a educaçáo no sentido de formar trabalhadores que vão para as fábricas e que vão utilizar os fatores-chave da criaçáo de riqueza: a terra, o capital, o trabalho, a energia, a matériaprima. A preparação para o trabalho surge pois como o seu principal objetivo, enquanto a questáo do conhecimento permanece relegada para um plano secundário. A prioridade é educar no trabalhador as atitudes, as disposiçóes, as formas de comportamento, conduta e aceitaçáo das relaçóes sociais imperantes. (BIANCHETTI; PALANGANA, 2000, p.43). O racionalismo constituiu-se no fundamento intelectual da nova ordem económica e social. No entanto, para lá de dar resposta às necessidades de formação requeridas pela nova economia do mundo industrializado, a criação dos sistemas escolares assenta, designadamente na Europa, numa dimensão política que visa consolidar os 'novos' estadosnação, contribuindo para a formação da identidade cívica, cultural e nacional e para o desenvolvimento do sentimento de pertença das suas populaçóes (cf. NÓVOA, 1998).

Surgiu assim um modelo de organização de escola que se desenvolve e consolida na viragem do século. A este conceito de escola associa-se um conjunto de características formais no que se refere à organização do espaço e sua delimitação, à organizaçáo de classes homogéneas de alunos, à definição rígida de horários escolares que exercem um controlo social do tempo (NÓVOA, op. cit.). Neste modelo, que ainda hoje persiste, o ensino é centrado no professor, e os saberes, predefinidos, são compartimentados em disciplinas. $\mathrm{O}$ currículo, campo permeado de ideologia, cultura e relaçóes de poder, é marcado por uma conceçáo instrumental e tecnológica, constituindo-se como instrumento planeado cientificamente para prever e controlar a escola em todas as dimensóes. Destinava-se a moldar o aluno com o máximo de eficácia e o mínimo de custos. Como salientam Beyer e Liston, "o modelo fabril do desenvolvimento do Currículo que emerge [na sociedade industrial] (...) realça a racionalidade técnica do processo-produto ligada a uma ênfase na eficácia e produtividade" (BEYER; LISTON, 1996, p. 22).

Outras inovaçóes educacionais subsidiárias do mundo do trabalho emergem, constatando-se que no seu conjunto o aparato teórico-prático mobilizado em torno e a partir da tecnologia tem por base a taylorizaçáo do processo educacional (BIANCHETTI; PALANGANA, 2000).

A Revolução Industrial veio assim provocar profundas alteraçóes que são económicas, que são sociais, mas que são também alteraçóes de crenças, alteraçôes de valores, alteraçóes da forma de ver o mundo.

Mas outra revolução, de grande magnitude e importância, se desencadeou. Com a emergência das tecnologias digitais, à semelhança do que aconteceu na época da Revoluçáo Industrial, a sociedade está a alterar-se profundamente. Alterase a forma como trabalhamos, a forma como pensamos, como aprendemos, alteram-se as formas tradicionais de comunicação. Vivemos ainda um processo de transição de um mundo tipicamente industrial, onde a terra, o trabalho, o capital e a energia constituíam os fatores de produção cruciais para criar riqueza e desenvolvimento, para uma sociedade onde o fator-chave da produção, aquilo que faz o desenvolvimento de um país, passou a ser outra coisa que não energia, que não a matériaprima, mas sim o conhecimento, como referimos na abertura deste texto.

De novo se assistem a alteraçóes profundas do ambiente económico e social, de novo as crenças estabelecidas são abaladas e novos valores se impóem. De novo a maneira de ver o mundo está a mudar. Vivemos uma mudança de era que impóe a necessidade de alteraçóes profundas, designadamente na educação, alteraçóes que autores como Ivan Illich ou Paulo Freire, entre outros, vêm reclamando desde os anos 60 do século passado, mas que agora se tornam verdadeiramente incontornáveis. A sociedade industrial deu lugar à sociedade do conhecimento. 
Cada era histórica cria um sistema educacional que atende as suas necessidades próprias. Assim, o sistema da sociedade industrial requeria uma educação de competências produtivas especializada, onde a alfabetização e a aprendizagem da aritmética constituíam as competências-chave para o desenvolvimento eficiente do processo produtivo (TUOMI, 2013). Por outro lado, como refere Tuomi (Op.cit.) a educação, para lá dos efeitos em nível da produção, gera também atitudes e conhecimentos que subjazem aos sistemas políticos e culturais e fornecem a base para a sociedade: "This is the 'cultural transfer' and 'enculturation' function of education. Education is required to make full social participation possible". (Op. Cit. p. 66). A esta função de "transferência cultural" a educação moderna veio acrescentar a importância do desenvolvimento pessoal e $o$ "pleno cumprimento do homem, em toda a riqueza da sua personalidade" (cf. relatório Learning To Be da UNESCO, FAURE et al., 1972).

Consoante os contextos históricos, sociais, económicos, culturais e políticos, assim se processa a educação. A transformação da sociedade industrial para a sociedade do conhecimento muda profundamente as condiçóes de desenvolvimento das funçôes sociais da educação e muda igualmente os seus objetivos e a abordagem pedagógica a realizar. A preparação para a vida ativa num mundo de trabalho precário, a volatilidade dos mercados, a construção de competências para atuar num mundo imprevisível e em permanente mudança, requer, também, a transformação das pedagogias no sentido da passagem do modelo transmissivo, que continua a caracterizar os sistemas educativos ocidentais, para modelos mais autónomos que privilegiem a iniciativa, a inovação, a participação e a coresponsabilização dos alunos pela sua própria aprendizagem (FIGUEIREDO, 2016)

\section{PAPEL DA EDUCAÇÃO A DISTÂNCIA: O CASO DA UNIVERSIDADE ABERTA DE PORTUGAL}

Que se tem passado, especificamente, com a educação a distância? Desde sempre esta modalidade de educação, que teve a sua origem na sociedade pós-industrial, tem estado ligada à necessidade de incluir social e profissionalmente pessoas que, por diversas circunstâncias, não podiam atender a sistemas de ensino presencial.

Basta recordarmos o que esteve na base da criaçáo da pioneira Open University (OU), no Reino Unido, que ainda hoje constitui uma referência maior na EaD. Quando Harold Wilson, 10 ministro trabalhista, apoiou a criação da Open University, em 1965, tinha em vista modernizar a sociedade britânica e criar uma economia mais competitiva, mas ao mesmo tempo, promover maior igualdade de oportunidades e provocar a mobilidade social.

Como assinala Weinbren (2015) no seu livro The Open University: A History, no discurso inaugural como chanceler da Fundação da OU em 1969, Geoffrey Crowther declarou a nova instituição "aberta de muitas maneiras, mas antes de tudo às pessoas". $\mathrm{Na}$ verdade, o compromisso com a inclusão era primordial e foi vinculado a uma "missão de resgate educacional". Contudo, a forma como os alunos avaliam as suas experiências e percurso indicam o impacto académico da $\mathrm{OU}$, mas simultaneamente apontam transformações pessoais que, de acordo com Weinbren, foram muito além da noção de resgate educacional. A OU mudou, para melhor, a vida de milhares de alunos:

As their own ability to make meanings became more sophisticated, OU students were better equipped to transform their own lives and recognize changes in the lives of those around them. This helped in turn to shape the university and the society in which it was embedded". (WEINBREN, 2015, p.231)

Poderíamos juntar, a esse exemplo emblemático da OU, todo um conjunto de outras universidades de educação a distância que foram, especialmente ao longo das últimas décadas do séc. XX, cumprindo 
indiscutível missão de inclusão e de mobilidade social que passou a fazer parte do "ADN" da $\mathrm{EaD}$, ainda na sua modalidade pré-internet. Porém, deter-nos-emos apenas em mais um exemplo, Portugal, considerando o particular conhecimento que temos desta realidade.

Em 1975, um ano após a Revolução Portuguesa, o relatório de uma comissão ad-hoc recomendava a criação de uma universidade de ensino a distância e apresentava um modelo possível, que constituiu o primeiro passo importante no sentido da criação de uma universidade a distância em Portugal. Em 1976, foi criada a Uniabe - Universidade Aberta, com o objetivo de contribuir para o progresso da democracia. Mas, apesar das boas intençôes, o decreto náo chegou a ser posto em prática.

Um impulso significativo ao reconhecimento interno da necessidade de criar uma universidade aberta com um projeto ajustado às características específicas da sociedade portuguesa foi dado pela European Association of Distance Teaching Universities, criada em 1987. Uma recomendação do Parlamento Europeu sobre o significado de universidades abertas na construção da Europa e a crescente importância dada pelos responsáveis da Comunidade Europeia ao mesmo problema contribuíram para ultrapassar as dificuldades apresentadas por várias entidades portuguesas com poder de decisão. Em 1988, na cerimónia de encerramento da conferência Long Term Developments for European Distance Education, realizada em Lisboa com representantes de todas as universidades abertas europeias, foi anunciada publicamente pelo Ministério de Educação português a decisão de se criar uma Universidade Aberta em Portugal.

A Universidade Aberta (UAb) é, assim, a mais recente universidade pública portuguesa, sendo a única instituição pública de ensino universitário a distância existente em Portugal. Vocacionada para a educação ao longo da vida e para a formação de cidadãos em idade ativa, apresenta-se como a instituição com possibilidade de responder às necessidades de formação graduada de nível superior, pós-graduada e contínua e à actualização de competências de profissionais dispersos e radicados longe dos centros de formação, quer em Portugal quer entre os milhóes de falantes de língua portuguesa (QUINTAS-MENDES; GRAVE, 2004). Tem, ao longo dos seus quase 30 anos, cumprido uma missão de assinalável relevância social, quer dando resposta a pedidos concretos emanados do Ministério da Educação, designadamente ao nível da profissionalização de milhares de professores, que náo detinham formação pedagógica para o exercício da profissão, (cf. AMANTE, 2011), quer possibilitando a formação em áreas de saber diversas a todos aqueles que encontram nesta modalidade de educaçáo uma porta de acesso ao conhecimento, à qualificação e simultaneamente à ascensão profissional e social.

\section{EVOLUÇÃO DOS SISTEMAS DE EDUCAÇÃO A DISTÂNCIA}

Como universidade de ensino a distância, a Universidade Aberta, à semelhança das suas congéneres europeias, desenvolveu formas de produção de materiais, de tutoria e de avaliação formativa baseadas nos princípios da autoaprendizagem. De facto o sistema clássico das universidades de ensino a distância e portanto também o sistema de ensino a distância da UAb era tradicionalmente baseado na autoaprendizagem, através do uso de manuais escritos, videogramas e audiogramas, emissóes de rádio e televisão. Era portanto um sistema convencional que privilegiava a interacção estudante-conteúdos, ainda que existissem interacçóes ocasionais estudanteprofessor através de um sistema de tutoria escrita ou telefónica.

Com a acelerada evolução tecnológica, a forma e o papel da educaçáo a distância sofreram muitas alteraçôes. A comunicação mediada por computador revolucionou efetivamente a $\mathrm{EaD}$, assistindo-se a uma verdadeira mudança de paradigma, como assinalaram, entre outros, Harasim, (2000) e Garrison, (2000), designando o resultado dessas alteraçôes como a "terceira geração do ensino a distância". 
Os sistemas de $\mathrm{EaD}$ industriais e massificados, centrados fundamentalmente na autoaprendizagem $\mathrm{e}$ em que o isolamento do estudante era uma constante, evoluíram para novos espaços pedagógicos onde a interação assume papel primordial, dando lugar à construção conjunta de aprendizagens, ultrapassando a mera transmissão e consumo de informação. Nos novos espaços a $\mathrm{EaD}$ passou a assentar essencialmente em ambientes virtuais de aprendizagem (AVA), sendo designada frequentemente como Educação Online e/ ou e-learning.

Tornaram-se possíveis, mesmo na ausência de presença física de estudantes e professores, múltiplas formas de interação bilateral e multilateral (um para um, um para muitos, muitos para muitos) dando lugar à existência de vastas redes de aprendizagem e de múltiplas formas de aprendizagem colaborativa. Abriu-se assim a possibilidade de o ensino a distância deixar de ser uma educação distante. $\mathrm{O}$ aluno (anteriormente isolado) através de uma plataforma de e-learning passava a poder participar numa comunidade de aprendizagem contextualizada. A EaD ganha entáo a "sala de aula", até aí ausente, e com ela a dimensão social da aprendizagem que possibilita e favorece a emergência de modelos construtivistas que apelam à construçáo coletiva do conhecimento (MORGADO, 2003). Para Harasim (2000), é precisamente essa combinação de atributos específicos da $\mathrm{EaD}$ (independência de espaço, tempo e comunicação centrada na escrita) com a possibilidade de interação em grupo (típica do ensino presencial) que tornam a educação a distância online um novo domínio educacional permitindo o emergir de um novo paradigma de aprendizagem.

Como sucedeu na generalidade das outras universidades abertas, a UAb promoveu mudanças significativas, determinadas pela evolução tecnológica e pelos novos modelos de ensino a distância que começaram a emergir nesse âmbito. Inicia as primeiras experiências de formação em contexto online, no início do novo milénio (PEREIRA et al. 2003; 2006; QUINTAS-MENDES; CRATO, 2004), tendo desenvolvido o próprio modelo pedagógico virtual (PEREIRA et al. 2007) e alterado então profundamente o seu modelo de $\mathrm{EaD}$ e a metodologia de trabalho adotada.

O referido modelo, validado por conselho consultivo internacional (cf. TEIXEIRA, 2007) estruturou-se com base em quatro grandes linhas de força:

- A aprendizagem centrada no estudante:

No centro do modelo apresentado situa-se o estudante, enquanto indivíduo activo, construtor do seu conhecimento, empenhando-se e comprometendo-se com o seu processo de aprendizagem e integrado numa comunidade de aprendizagem.(PEREIRA et al., 2007, p.10).

- O primado da flexibilidade:

Uma das vantagens do ensino a distância radica na possibilidade de o estudante aceder aos conteúdos e às actividades de aprendizagem ou de resolver as tarefas a ela correlativas de forma flexível, sem imperativos temporais ou de deslocação (Não Coincidência no Tempo/ Não Coincidência no Espaço). Um modelo essencialmente assíncrono permite a não-coincidência de espaço e nãocoincidência de tempo na medida em que a comunicação e a interacção se processa à medida que é conveniente para o estudante, possibilitando-lhe tempo para ler, processar a informaçáo, reflectir e, entáo, dialogar ou interagir (responder). (Op. Cit. p.12)

A ênfase nas tecnologias assíncronas pretende precisamente reforçar este princípio da flexibilidade, permitindo ao estudante maior flexibilidade na gestão temporal da aprendizagem, definindo em funçáo da sua disponibilidade os tempos de acesso online, de pesquisa individual, de estudo e aprofundamento dos temas e de interação com o professor e os colegas.

- O primado da interação:

Se nas primeiras geraçôes de ensino a distância a interação era fundamentalmente entendida como interacção estudante-conteúdo e interacção estudante-professor, no modelo aqui explicitado ela alarga-se de forma decisiva à interação estudante-estudante, através da criação de grupos de discussão no interior de cada turma virtual, 
implicando o seu planeamento prévio (o desenho instrucional) e estratégias de ativação da aprendizagem, de modo a estimular a iniciativa e o envolvimento dos estudantes, bem como a garantir o seu empenhamento e orientar a natureza do seu trabalho. (Op. Cit. p.13)

- O princípio da inclusão digital:

(...) ao invés de exigir como requisito prévio para o acesso à universidade a familiaridade com as modernas ferramentas tecnológicas, assume-se como um objectivo educacional central da Universidade Aberta a promoção de estratégias educativas que contribuam para a aquisição e desenvolvimento da literacia digital dos estudantes. (Op. Cit. p.15)

Essa linha de força da inclusão digital dos estudantes leva a que todos os programas de formação certificados pela UAb incluam um módulo designado "Módulo de Ambientação Online" (MAO). Como assinalam Souza, Spilker e Amante (2015), esse módulo, realizado online previamente ao início de cada semestre letivo e destinado aos novos estudantes, visa a aquisição de um conjunto de competências base, não só de natureza tecnológica, como de natureza sociopedagógica.
Coloca-se a ênfase no desenvolvimento de competências relativas à comunicação online e no que caracteriza o "ser estudante online", considerando o contexto particular da formaçáo em causa e as especificidades do modelo pedagógico da instituição.

A mudança então encetada exigiu vasto programa de inovação que implicou a concretização de complexo plano de formaçáo dos docentes da universidade com vista à apropriação de novas metodologias de trabalho pedagógico, e ainda a adaptação de todo o aparelho administrativo e técnico aos novos requisitos de uma universidade digital. $\mathrm{O}$ quadro 1 dá conta da evolução do modelo convencional de EaD para o novo modelo virtual, nas suas duas variantes, $1^{\circ}$ ciclo (cursos de graduação) e $2^{\circ}$ e $3^{\circ}$ ciclo (cursos de pós-graduação), considerando as suas principais características.

Quadro 1 - Evolução do modelo convencional de EaD para o modelo pedagógico virtual na UAb

\begin{tabular}{|l|l|l|l|}
\hline & $\begin{array}{l}\text { Modelo Convencional: } \\
\text { Autoaprendizagem }\end{array}$ & $\begin{array}{l}\text { E-Learning: Modelo para a } \\
\text { Graduação }\end{array}$ & $\begin{array}{l}\text { E-Learning: Modelo para } \\
\text { Pós-Graduação }\end{array}$ \\
\hline$N^{\circ}$ de estudantes & llimitado & Turmas de 60 estudantes & Turmas de 25 estudantes \\
\hline $\begin{array}{l}\text { Interação Estudante } \\
\text { Conteúdos }\end{array}$ & $\begin{array}{l}\text { Alguma Interatividade está } \\
\text { incorporada nos conteúdos: } \\
\text { Exercícios, atividades } \\
\text { de Autoaprendizagem; } \\
\text { "Feedbacks" previamente } \\
\text { organizados }\end{array}$ & $\begin{array}{l}\text { Atividades Formativas com } \\
\text { feedback previamente } \\
\text { organizado; } \\
\text { Exercícios e pequenos } \\
\text { testes, resolução de } \\
\text { problemas, participação em } \\
\text { discussões, relatórios. }\end{array}$ & $\begin{array}{l}\text { Forte Diálogo e Interação } \\
\text { sobre os Conteúdos. } \\
\text { Projetos, Ensaios, etc. }\end{array}$ \\
\hline $\begin{array}{l}\text { Interacção } \\
\text { Professor/Tutor-Estudante }\end{array}$ & Ocasional & $\begin{array}{l}\text { Em momentos previamente } \\
\text { definidos do Curso }\end{array}$ & Constante \\
\hline $\begin{array}{l}\text { Interacção } \\
\text { Estudante Estudante }\end{array}$ & Inexistente & Constante & Constante \\
\hline Avaliação & Exame presencial & $\begin{array}{l}\text { Avaliação Contínua e } \\
\text { Avaliação Presencial Final }\end{array}$ & Avaliação contínua \\
\hline
\end{tabular}

Fonte: Autores 
O Modelo Pedagógico Virtual da Universidade Aberta é assim um modelo de e-learning que assenta fundamentalmente em ferramentas de comunicação assíncrona. Estas são ferramentas que permitem assegurar maior flexibilidade temporal e espacial durante o processo de aprendizagem. Os estudantes podem aceder aos seus cursos a qualquer hora e a partir de qualquer lugar do mundo.

\section{DA EDUCAÇÃO A DISTÂNCIA À EDUCAÇÃO ABERTA}

Se é um facto que a $\mathrm{EaD}$, desde a sua origem, contribuiu para democratizar o acesso à educação, promovendo maior justiça social, os seus desenvolvimentos recentes suportados pelas inovaçôes tecnológicas no campo educacional vieram acentuar ainda mais a ideia da diversidade de oferta e de acesso, independentemente do lugar, do espaço, do tempo e de outras condicionantes (GRANT; VILLALOBOS, 2008). Assim, "grupos que habitualmente estáo ausentes das formas convencionais de educação, após a escolaridade obrigatória, têm atualmente novas oportunidades de ser re-envolvidos em processos de aprendizagem e de educação" (AMANTE, 2013, p. 165), encontrando na $\mathrm{EaD}$ uma porta de acesso ao conhecimento certificado e com ele a profissóes mais qualificadas a que se liga a ascensão social, bem como maior participaçáo cidadá que decorre desse acesso à informação e à cultura.

É um facto que a Internet e a World Wide Web têm na sua base uma arquitetura de abertura, de participação, de inexistência de hierarquia (SELWYN, 2011), levando a que a tecnologia se tenha associado, nos últimos 20 anos, a conceitos de educação equitativa, descentralizada, democrática, baseada nas necessidades individuais dos seus utilizadores (GRAHAM, 2002).

Com efeito, as tecnologias digitais surgem conotadas com o conceito de liberdade e de inclusão, e se elas são hoje indissociáveis da $\mathrm{EaD}$, não se restringem a ela. Cada vez mais as tecnologias permeiam os sistemas de educação ditos presenciais e cada vez mais estão permitindo um acesso ao conhecimento fora dos circuitos de educação formal. É o caso dos MOOCs (Massive Open Online Courses), que se configuram como oportunidades educativas de excelência. Semelhantes aos cursos universitários, embora não oferecendo creditação académica convencional, são cursos abertos de acesso gratuito e não exigem pré-requisitos de participação, podendo abranger número massivo de alunos.

Weller (2009) salienta que se começassemos agora a criação de uma universidade aberta, ela seria construída de modo muito diferente. Defende que a noção de abertura seria indissociável de um projeto dessa natureza, ou seja, indissociável do uso de software livre, de recursos educacionais abertos, de práticas educacionais abertas, pesquisa aberta, cursos abertos, sistemas abertos. Considera que o custo da partilha desapareceu e que essa partilha pode transformar a prática.

As universidades de $\mathrm{EaD}$ e as universidades abertas, impulsionadas pela evolução das tecnologias digitais, têm efetuado grandes mudanças e continuam a mudar. Parecem estar assim particularmente vocacionadas para dar resposta ao apelo contemporâneo quanto à abertura, à inclusão e ao desenvolvimento de práticas pedagógicas inovadoras que a sociedade atual exige.

$\mathrm{Na}$ verdade, para lá das grandes mudanças já reportadas que levaram à migração da $\mathrm{EaD}$ para plataformas online e a uma mudança radical da abordagem pedagógica típica da $\mathrm{EaD}$ pré-internet, é hoje impossível discutirmos $\mathrm{EaD}$ e inclusão sem que se discuta outro conceito, o conceito de educação aberta.

A esse propósito, a Declaração da Cidade do Cabo de 15 de setembro de 2007 afirma:

Educators worldwide are developing a vast pool of educational resources on the Internet, open and free for all to use. These educators are creating a world where each and every person on earth can access and contribute to the sum of all human knowledge. They are also planting the seeds of a new pedagogy where educators and learners create, shape and evolve knowledge together, deepening their skills and understanding as they go. (CAPE TOWN OPEN EDUCATION DECLARATION n.p.) 
Porém o conceito de abertura não é fácil de definir. Ainda antes da emergência da Internet, Rumble (1989) assinalou a importância de distinguir entre educação a distância e educação aberta. Considerava essencial distinguir esses conceitos partindo de um conjunto de características de abertura que reuniu em 5 categorias: 1) Critérios relacionados com o acesso (finanças, idade, prérequisitos, etc.); 2) lugar e ritmo de estudo; 3) meios (referindo-se à escolha do media a usar); 4) estrutura do programa (definiçáo dos objetivos de aprendizagem, conteúdos a incorporar ou excluir) e 5) serviços de suporte.

Para Bates (2016), a aprendizagem aberta é, antes de mais, um objetivo ou uma política educacional, e sua característica essencial prende-se com a remoção de barreiras à aprendizagem. Considera que a aprendizagem aberta tem implicaçóes particulares no uso da tecnologia, no entanto, a abertura na sua forma mais pura é raramente encontrada. Nenhum sistema de ensino é completamente aberto, requerendo sempre um mínimo de literacia, que permita aceder-lhe. Este autor caracteriza a educaçáo aberta em diversas vertentes: a) educação para todos, no sentido da gratuitidade ou do baixo custo da formação; b) acesso aberto a programas, oferecidos regra geral por universidades abertas e que permitem qualificaçóes plenas; c) acesso aberto a cursos ou programas que não são de crédito formal, como o caso dos MOOCs (Massive Open Online Courses); d) recursos educacionais abertos, utilizados por docentes e estudantes de modo gratuito; e) livros abertos, livros didáticos disponibilizados livremente aos alunos; $f$ ) pesquisa aberta, relacionada com a disponibilização online de trabalhos de pesquisa, para download livre e g) dados abertos, ou seja, disponibilização de dados que podem ser utilizados, reutilizados e redistribuídos, sem restriçóes.

Parte das grandes alteraçóes ocorridas em $\mathrm{EaD}$ rumo a uma educação mais aberta e mais participada estão intrinsecamente ligadas à emergência da chamada Web 2.0, que contextualiza, e em parte gera, a emergência de novas práticas de educação aberta e a distância.
A Web 2.0 incorpora recursos e potencialidades até há pouco tempo inexistentes na Internet nomeadamente através do chamado "software social" que permite que indivíduos, grupos, redes e coletivos atuem, interatuem e aprendam de forma colaborativa e em rede (DRON \& ANDERSON, 2014). Proporciona um espaço de participação ativa, que ao ser usado num processo de ensino/aprendizagem propicia a emergência de ambientes de pesquisa, de participação, de criação, de colaboraçáo e de cooperaçáo entre todos os envolvidos. Assim, constitui-se como o ambiente ideal para a construçáo da inteligência coletiva, transcendendo o espaço e o tempo das inteligências individuais que a formam.

Também Brown e Adler (2008) assinalam:

The latest evolution of the Internet, the so-called Web 2.0, has blurred the line between producers and consumers of content and has shifted attention from access to information toward access to other people. New kinds of online resources-- such as social networking sites, blogs, wikis, and virtual communities have allowed people with common interests to meet, share ideas, and collaborate in innovative ways. Indeed, the Web 2.0 is creating a new kind of participatory medium that is ideal for supporting multple modes of learning. (Op. Cit. p 18)

Essa participação remete-nos para o conceito de "cultura participatória" introduzido por Jenkins et al. (2006). O conceito de "cultura participatória" entende os utilizadores dos media como participantes ativos e criativos que interagem para criar e partilhar novos conteúdos, assumindo uma atitude mais produtiva e sociável. Contudo Jenkins defende que apesar de a tecnologia fornecer a infraestrutura que permite a interação e a afiliação dos indivíduos a determinados grupos, ela, só por si, não garante a sua participação. Green e Jenkins (2009) alertam que "cultura participatória" e Web 2.0, embora ligadas, não devem ser confundidas. Argumentam que apesar de uma retórica de colaboração e de pertença a uma comunidade, muitos sites da Web 2.0 referem-se a um conjunto de práticas comerciais que buscam capturar e aproveitar as energias criativas e a inteligência coletiva dos seus utilizadores. 
Concebem-nos como sujeitos que se relacionam fundamentalmente com a empresa e não com a comunidade de utilizadores. Assim, ao transpor o modelo de negócios da Web 2.0 para práticas educacionais, corre-se o risco de ver os alunos como "consumidores" em vez de verdadeiros "participantes" dentro do processo educacional. $\mathrm{Na}$ "cultura participatória" o fundamental é o grupo e a relação de conexão social estabelecida, levando a que os membros participem e acreditem que as suas contribuições são importantes para o coletivo (JENKINS et al., 2006).

\section{RECURSOS EDUCACIONAIS ABERTOS (REA), PRÁTICAS EDUCACIONAIS ABERTAS (PEA) E AMBIENTES PESSOAIS DE APRENDIZAGEM (APA)}

É assim, na nova fase da internet, que foram criadas condiçóes que permitiram o aparecimento dos recursos educacionais abertos (REA) e das práticas educacionais abertas (PEA), proporcionando novo avanço nas formas de criação, partilha $\mathrm{e}$ disseminação do conhecimento humano.

Em 2001, o Massachussets Institute of Technology (MIT) criou o OpenCourseWare ${ }^{1}$, com o objetivo de disponibilizar grande parte dos materiais relacionados com os seus cursos de graduação e pós-graduação para acesso ao público em geral, com a finalidade de ensino, aprendizagem e pesquisa. No ano seguinte o termo "Open Education Resources", foi usado pela primeira vez em julho de 2002 durante o Forum on the Impact of Open Courseware for Higher Education in Developing Countries e definido como: "The open provision of educational resources, enabled by information and communication technologies, for consultation, use and adaptation by a community of users for noncommercial purposes" (JOHNSTONE, 2005; PAWLOWSKI et al., 2012). Já em 2012 os REA foram referidos na Declaração de Paris Sobre Recursos Educacionais Abertos, como sendo:

\footnotetext{
${ }_{1}$ Disponível em https://ocw.mit.edu/index.htm (acedido em 01/08/2017)
}

(...) os materiais de ensino, aprendizagem e investigação em quaisquer suportes, digitais ou outros, que se situem no domínio público ou que tenham sido divulgados sob licença aberta que permite acesso, uso, adaptação e redistribuição gratuitos por terceiros, mediante nenhuma restrição ou poucas restrições. O licenciamento aberto é construído no âmbito da estrutura existente dos direitos de propriedade intelectual, tais como se encontram definidos por convençóes internacionais pertinentes, e respeita a autoria da obra.. (UNESCO, 2012).

Segundo a própria definição da Unesco, os REA podem incluir desde livros didáticos e artigos académicos até aulas e cursos completos, além de software, vídeos, ferramentas, materiais ou técnicas que possam apoiar a aprendizagem e o acesso ao conhecimento. Os REA tornam-se nos nossos dias um recurso de grande potencial para todos aqueles que querem aprender, colaborar e partilhar informação, fundamentalmente por permitirem disponibilizar o acesso a oportunidades de aprendizagem àqueles que não tenham possibilidade de obtê-lo de outras formas. O exemplo mais emblemático de REA refere-se ao Projeto Wikipédia, a enciclopédia livre online, construída com o contributo de uma comunidade de voluntários em todo o mundo através de uma tecnologia Wiki e que atingiu amplitude sem precedentes. Este projeto, iniciado em 2001 em língua inglesa, rapidamente se disseminou e popularizou.

Sob a licença Creative Commons BY-SA, o seu conteúdo pode ser copiado e reutilizado constituindo um marco das possibilidades do trabalho colaborativo (PESTANA, 2014). Para além do inegável contributo para a democratização do acesso à informação, o projeto Wikipédia, tendo na sua essência o conceito de inteligência coletiva (LÉVY, 1998) é claro exemplo de construção social de conhecimento, de livre participação e da atualização constante do saber que caracterizam os REA.

Assim, a educação aberta, apesar de ter raízes mais antigas, ganhou novos impulsos a partir do movimento dos REA (constituindo este, de certa forma, uma aplicação dos princípios do open source à 
produção e distribuição de conteúdos educacionais) e que se prolonga em movimentos como os dos open online courses, open research, open data e open access (WELLER, 2012). No entanto várias críticas têm surgido relativamente a esse movimento, uma vez que parece estar implícita a ideia de que a simples disponibilizaçáa de recursos educacionais em repositórios garantiria um acesso mais justo e equitativo à educação (KNOX, 2013). Surge nesse contexto a noção de práticas educacionais abertas (PEA), conceito relativamente recente que decorre de um processo de amadurecimento e desenvolvimento do movimento dos recursos educacionais abertos:

As Práticas Educacionais Abertas afiguram-se como práticas colaborativas, com base na partilha de recursos no contexto de práticas pedagógicas por sua vez centradas na interação social, criação de conhecimento, aprendizagem com os pares e práticas de aprendizagem partilhadas" (CARDOSO, 2013).

Trata-se de movimento heterogéneo de pessoas e instituiçóes que busca oferecer novas e variadas oportunidades de aprendizagem com base, principalmente, em recursos educacionais disponíveis em regime aberto, visando tornar a educação mais livre e acessível para todos (INUZUKA; DUARTE, 2012). A educação aberta online assume entâo novo protagonismo, tendo os REA e as PEA papel fundamental no seu desenvolvimento e amadurecimento (CARDOSO, 2016).

Não basta pois um acesso aberto generalizado, são necessários usos e reúsos contextualizados, autorias e coautorias inseridas em práticas pedagógicas concretas. A interaçáo social proporciona a passagem de um modelo de transferência para um modelo de práticas sociais. E, tal como a noção de PEA vem questionar de uma forma dinâmica os REA, também a noção de ambiente pessoal de aprendizagem (APA) vem questionar, como prática social e educacional aberta, as formas de ensino e aprendizagem mais fechadas protagonizadas pela utilização das tradicionais Plataformas de E-Learning (MOTA, 2009). Já num texto de 2008 intitulado Systematization of Education: Room for
PLEs?, George Siemens (2008, apud MOTA, 2009) exprimia a sua insatisfação pelos poucos progressos que, na sua perspetiva, tinham sido feitos na transição dos ambientes fechados das instituiçóes para os ambientes abertos e personalizados dos PLEs (Personal Learning Environement), ou seja, dos APA.

O conceito de ambiente pessoal de aprendizagem surgiu de discussóes entre amplo grupo de profissionais interessados em projetar e desenvolver ambientes online de aprendizagem (MOTA, 2009). Para alguns, o APA é uma ferramenta específica ou uma coleção de ferramentas usadas por um estudante para organizar o próprio processo de aprendizagem. Para outros, o APA é uma metáfora para descrever as atividades de um aluno moderno online. Não existe de facto uma definiçáo amplamente aceite, no entanto, um traço comum em todas as definiçóes iniciais de um APA é que este dá ao sujeito controlo sobre o seu próprio processo de aprendizagem (MOTA, 2009; COUROS, 2010; MARTINDALE; DOWDY, 2010).

Okada et al. (2009) propuseram o conceito de "coletividades abertas de pesquisa" que, de acordo com estas investigadoras, são grandes aglomerados de utilizadores da Web, muitas vezes desconhecidos entre si, que utilizam as mesmas tecnologias e que podem assim trocar informaçóes e conhecimentos em face de seus interesses, necessidades e motivações. Permitem-se criar espaços de comunicação, de aprendizagem, partilha e colaboração em que se encontram materiais de ensino, aprendizagem e pesquisa, licenciados de maneira aberta, e que podem ser utilizados ou adaptados e reutilizados por terceiros (OKADA, 2011). Esses espaços de comunicação, colaboraçáo e aprendizagem podem definir-se como espaços rizomáticos que encorajam os participantes a explorar múltiplas representaçóes da realidade e de processos colaborativos de construção do conhecimento. O rizoma, um processo de contínua diferenciação em torno de uma raiz, foi posto em contraste por Deleuze e Guatarri (1983) com os tradicionais modelos hierárquicos de construção do conhecimento. 
Neste sentido, Duffy e Cunningham (2001) sugeriram que usar a metáfora do rizoma para conceber a mente é uma forma adequada de conceber as práticas construtivistas e conectivistas de ensino e aprendizagem, em particular no que respeita à utilização de estratégias colaborativas. Para estes autores, learning, then, is [...] a matter of constructing and navigating a local, situated path through a rhizomous labyrinth, a process of dialogue and negotiation with and within a local sociocultural context' as opposed to a singularly desired, imposed and predetermined outcome (Op. cit. 2001, n.p.).

É neste contexto que as práticas pedagógicas centradas na produção de artefactos digitais abertos, que apelam à reutilização e à coautoria, deslocam o eixo dos recursos educacionais abertos para o das práticas educacionais abertas e o eixo da aprendizagem quase exclusivamente centrada em plataformas de e-learning (Learning Management Systems - LMS) para uma prática de articulação entre os LMS e Ambientes Pessoais de Aprendizagem (DALSGAARD, 2006).

Anderson (2006) salientou várias vantagens dos APA sobre as Plataformas de E-learning tradicionais. Com o APA o estudante tem um sentido de si e de identidade para além da sala de aula. Dirige a própria aprendizagem, assume responsabilidade pelos seus conteúdos, controla e organiza o próprio ambiente de trabalho, em vez de operar dentro de um ambiente que faz essencialmente sentido para o professor ou para a instituição. Deixa de ser um consumidor passivo, tem agora um papel de autor e produtor. Muito para além do traço que deixa no LMS, o estudante desenvolve deste modo uma verdadeira personalidade online disseminada pela Net em graus variados (Op. Cit. 2006).

Por seu turno, Schaffert e Hilzensauer (2008) identificaram os desafios que os alunos enfrentam quando se propóem construir um APA como um meio de aprendizagem: é-lhes exigido que façam uma análise e seleção eficazes de conteúdos de aprendizagem, têm de usar várias ferramentas de uma só vez e de uma forma combinada, têm de compreender os pontos fortes das várias aplicações da Web 2.0, desenvolver conhecimento sobre os problemas da propriedade intelectual e, simultaneamente, é-lhes requerida uma motivação de natureza intrínseca para aprender. Isto implica todo um novo processo de trabalho rumo à aquisiçáo de novas literacias digitais com competências em diversas dimensões.

Assim, um dos principais focos do processo de ensino/aprendizagem passa a estar na produção de artefactos e nas representaçóes de conhecimento construídas pelos estudantes. Numa época em que o conhecimento está sempre acessível através de dispositivos digitais, a educação orientada para a memorização perde parte da sua importância. A memorização desenvolver-se-á, mas será uma consequência lateral do envolvimento profundo numa prática pedagógica (COPE; KALANTZIS, 2017). De facto, os objetivos de aprendizagem são diferentes numa época em que temos esses dispositivos omnipresentes num ambiente digital rico e complexo. O objeto mensurável da aprendizagem passa agora da memória em longo prazo para os processos de conhecimento e a sua documentação sob a forma de artefactos epistémicos ou representações de conhecimento - um relatório, uma soluçáo trabalhada, uma atividade gravada, um modelo, um projeto - dá lugar a produçóes digitais que podem ser tornadas públicas, que são partilháveis, eventualmente editáveis e reutilizáveis por outros.

\section{REFLEXÃO FINAL, VISANDO O FUTURO}

Como vimos, as transformações advindas da "revolução digital" na forma como sugerem novos processos de conhecimento e de aprendizagem, trazem desafios à educação. Mais do que instrumentos que proporcionam múltiplas atividades de aprendizagem, mais do que ferramentas cognitivas, mais do que bancos de dados e informações, a Web e o seu grande potencial de interação e comunicaçáo deu lugar à construçáo de novos espaços pedagógicos, de ambientes de aprendizagem com características específicas com novas dinâmicas sociais, novas formas de conceber 
o processo de aprendizagem. No ensino, em geral, o processo de apropriaçáo das tecnologias como novos instrumentos culturais de acesso e construção de conhecimento, tem sido lento.

Mas, como assinalam Moore e Kearsley (2008), a explosão do conhecimento, a especialização crescente $\mathrm{e}$ as novas tecnologias digitais estáo acelerando a desconstrução dos processos educacionais convencionais, provocando, apesar das resistências, uma desmontagem das funçóes executadas tradicionalmente pelas instituiçōes educativas. As instituiçôes educacionais têm mantido até aqui uma espécie de monopólio na oferta de ensino, porque controlam, ou melhor detêm o poder da certificação. Todavia, cada vez mais esse monopólio será posto em causa e a certificação tradicional, tal como a conhecemos, tenderá a perder o seu valor. Cada vez mais, serão os sujeitos a definir o que pretendem aprender e o processo típico que liga a formação a uma entidade formadora específica tenderá cada vez mais a desaparecer. $\mathrm{Ou}$ seja, cada vez mais a educação será vista como um sistema aberto, em que os alunos terão liberdade para reunir os programas de formação que melhor entendam servir os seus interesses, usando recursos diversificados, acedendo pela Web às instituições que os disponibilizam, independentemente do lugar onde estejam localizadas.

Mas enfrentar os desafios e oportunidades das tecnologias digitais não passa apenas pela inovação tecnológica, requer também a adoção de novas práticas pedagógicas. Como nos ensinou Jerome Bruner (2000), “a pedagogia nunca é inocente. É um meio que veicula a sua própria mensagem "(Op. cit. p.93). É necessário refundar as práticas pedagógicas, é necessária uma nova ideia de currículo, redefinir o papel dos professores, dos grupose das comunidades. Como sublinha Figueiredo (2016), o digital não pode ser visto meramente como instrumental, o digital protagoniza "imensa mutação sociocultural e económica” (Op. cit. p.19).

A $\mathrm{EaD}$ e a sua evolução, marcada pela adoção das tecnologias para melhorar os contextos de aprendizagem da $\mathrm{EaD}$ tradicional criando maior proximidade com os estudantes, veio conferir a essa modalidade de ensino (tradicionalmente vista como pobre em face do ensino presencial) uma posição de vanguarda. Tem vindo a revelar-se um exemplo ao nível da apropriação da inovação tecnológica e, simultaneamente, da inovação pedagógica. A EaD deu lugar ao questionamento de muitas práticas de educaçáo convencionais, assentes em modelos transmissivos, centrados nos conteúdos em detrimento dos processos, fechadas em formas de avaliação tradicionais, pouco transparentes e divorciadas da realidade (AMANTE, 2016).

Assim, a EaD tem permitido contribuir não só para o desenvolvimento da literacia digital das populaçóes abrangidas, como para a sua qualificação e inclusão social. Mas simultaneamente, tem vindo a operar mudanças no paradigma educacional (ainda) vigente, mobilizando nos estudantes capacidades de autonomia, de pesquisa, de seleção, de colaboração, promovendo novas formas de aprendizagem que se inscrevem num conjunto de competências e desempenhos onde se cruzam processos cognitivos e sociais, relevantes para a vida na sociedade atual. A EaD e o movimento da educação aberta, a que se ligam muitos conceitos educacionais inovadores, como os que abordámos neste texto (REA, PEA e $\mathrm{APA}$ ), constituem oportunidades para ampliar a formação e investir na qualificaçáo profissional e pessoal da população.

Está em causa profunda alteraçáo do mundo em que vivemos. $\mathrm{O}$ verdadeiro acesso aberto à educação, que atualmente vai além dos sistemas formais de $\mathrm{EaD}$, pode dar importante contributo para o desenvolvimento das competências que esse mundo em mudança requer aos cidadãos. Mas, além disso, esperamos que possa promover a emancipaçáo humana, a construção de uma humanidade plena, no sentido defendido por Adorno (1995) ou por Paulo Freire (1996), promovendo uma sociedade verdadeiramente aberta e inclusiva. 


\section{REFERÊNCIAS}

ANDERSON, T. PLEs versus LMS: Are PLEs ready for Prime time? 2006. Disponível em: <http://terrya.edublogs. org/2006/01/09/ples-versus-lms-are-ples-ready-for-prime-time/ >. Acesso em: 23 jul. 2017.

ADORNO, T.W. Educação e Emancipação. Rio de Janeiro: Paz e Terra, $1995.190 \mathrm{p}$.

AMANTE, L. Formaçáo de Professores a Distância: a experiência da Universidade Aberta de Portugal. Revista PerCursos, v. 12, n 1, p. 09-26, 2011. Disponível em: <http://www.periodicos.udesc.br/ index.php/percursos/article/view/2292>. Acesso em: 07 ago. 2017.

Tecnologias e Educação: novas possibilidades ou novas desigualdades? In: CAVALHERI, A; ENGERROFF, S.N.; SILVA, J.C. (Org.) As Novas Tecnologias e os Desafios para uma Educação Humanizadora. Santa Maria: Biblos Editora, p.159-180, 2013.

Cultura da Convergência e Universidade: Contributos da Educação a Distância. Revista de Educação Pública: educação e seus sentidos no mundo digital, v. 25, n 59, p.252-262, 2016.

BATES, T. Educar na era digital: design, ensino e aprendizagem. Artesanato Educacional: São Paulo, 2016. 640 p.

BEYER, L.; LISTON, D. Curriculum in conflict: social visions, educational agendas and progressive school reform. New York:Teacher College Press, 1996. 241 p.

BIANCHETTTI, L.; PALANGANA, I. Sobre a Relação Histórica entre Escola e Sistema Produtivo: Desafios Qualificacionais. Boletim Técnico do Senac, v. 26, n.2, p.40-51, 2000.

BROWN, J.S.; ADLER, R.P. Minds On Fire: Open Education, the Long Tail, and Learning 2.0. Educause Review, v.43, n.1, p.17-32, 2008.

BRUNER, J. Cultura da Educação. Lisboa: Ediçōes 70, 2000. 240 p.

CAPE TOWN OPEN EDUCATION DECLARATION. Cape Town Open Education Declaration: unlocking the promise of open educational resources. 2007. Disponível em:< http://www. capetowndeclaration.org/read-the-declaration >. Acesso em: 30 jul. 2017.

CARDOSO, P. Práticas Educacionais Abertas. Enciclopédia de Educação a Distância e E-Learning. 2013. Disponível em:< http://cnx.org/contents/1770796b-221c-446e-b20e7293f2563e29@1/Pr\%C3\%A1ticas_Educacionais_Abertas >. Acesso em: 02 ago. 2017.

Práticas Educacionais Abertas no Ensino Superior Público em Portugal: da teoria à prática - recursos educacionais abertos e acesso aberto. 2016. Tese (Doutoramento em Educaçáo, especialidade Educação a Distância e Elearning) - Universidade Aberta, Lisboa, 2016.
COPE, B.; KALANTZIS, M. Conceptualizing e-Learning. In: COPE, B.; KALANTZIS, M. (Eds.) e-Learning Ecologies. Principles for New learning and Assessment. Routledge: New York, 2017. 218 p.

COUROS, A. Developing Personal Learning Networks for Open and Social Learning. In: VELETSIANOS, G. (Ed.) Emerging Technologies in Distance Education. Athabasca: Athabasca University Press, 2010. p.109-128.

DALSGAARD, C. Social software: e-learning beyond learning management systems. European Journal of Open, Distance, and E-Learning, n.2, 2006. Disponível em:< http://www.eurodl.org/ materials/contrib/2006/Christian_Dalsgaard.htm >. Acesso em: 20 jul. 2017.

DELEUZE, G.; GUATTARI, F. On the Line. New York: Semiotext(e), 1983.

DRON, J.; ANDERSON, T. Teaching Crowds: Learning and Social Media. Athabasca: AU Press, Athabasca University, 2014. 353 p.

DUFFY, T.; CUNNINGHAM, D. Constructivism: implications for the design and development of instruction. In: JONASSEN, D. H. (Ed.). Handbook of Research for Educational Communications and Technology. Bloomington: The Association for Educational Communications and Technology, 2001. Disponível em:< http://members.aect.org/edtech/ed1/ firstedition.asp >. Acesso em: 07 jul. 2017.

FAURE, E. et al. Learning to be. The world of education today and tomorrow. Paris: UNESCO, 1972. 313 p. Disponível em:< http:// unesdoc.unesco.org/images/0000/000018/001801e.pdf>. Acesso em: 30 jul. 2017.

FIGUEIREDO, A. D. Por uma escola com futuro para além do digital. Revista Nova Ágora, n. 5, p. 19-21, 2016.

FREIRE, P. Pedagogia da Autonomia: saberes necessários à prática educativa. São Paulo: Paz e Terra, 1996.165 p.

GARRINSON, D.R. Theoretical Challenges for Distance Education in $21^{\text {st }}$ Century: a Shift from Structural to Transactional Issues. International Review of Research in Open and Distance Education, v.1, n.1, p.1-17, 2000.

GRAHAM, S. Bridging urban divides? Urban Studies, v.39, n.1, p.33-56, 2002.

GRANT, L.; VILLALOBOS, G. Designing Educational Technologies for Social Justice. Bristol: Futurelab, 2008. 84 p. Disponível em:< http://vizdigcitper2014.weebly.com/uploads/1/8/3/8/18384971/ designing_for_social_justice2.pdf >. Acesso em: 25 jul. 2017.

GREEN, J.; JENKINS, H. The Moral Economy of Web 2.0. Audience research and convergence culture. In: HOLT, J.; PERRENP, A. (Ed.). Media Industries: history, theory, and method. Chichester: Wiley Blackwell, 2009. p.213-225.

HARASIM, L. Shift happens, online education as a new paradigm in learning. The Internet and Higher Education, v.3, n.1, p. 41-61, 2000. 
INUZUKA, M.; DUARTE, R. Produção de REA apoiada por MOOC. In: SANTANA, B.; Rossini, C.; PRETTO, N. (Orgs). Recursos Educacionais Abertos: práticas colaborativas politicas públicas. Salvador: Edufba; São Paulo: Casa da Cultura Digital, 2012, p.193-217.

JENKINS, H. et al. Confronting the challenges of participatory culture: Media Education for the 21st Century. Chicago: MacArthur Foundation, 2006. 68 p. Disponível em:< http:// digitallearning.macfound.org/atf/cf/\%7B7E45C7E0-A3E0-4B89AC9C-E807E1B0AE4E\%7D/JENKINS_WHITE_PAPER.PDF>. Acesso em: 30 jul. 2017.

JOHNSTONE, S. Open Educational Resources and Open Content, Background Note. International Institute for Educational Planning, Internet Discussion Forum on Open Educational Resources, Open Content for Higher Education. 2005. Disponível em: <http://www.unesco.org/iiep/virtualuniversity/media/forum/ oer_forum_session_1_n ote.pdf>. Acesso em: 12 jun. 2017

KNOX, J. The limitations of acess alone: moving towards open processes in education technology. Open Praxis, v.5, n.1, p. 2129, 2013.

LÉVY, P. A inteligência coletiva: por uma antropologia do ciberespaço. São Paulo. Ediçóes Loyola, 1998. 212 p.

MARTINDALE, T.; DOWDDY, M. Personal Learning Environments. In: VELETSIANOS, G. (Ed.). Emerging Technologies in Distance Education: Athabasca: Athabasca University Press, 2010. p.177-194.

MORGADO, L. Os Novos Desafios do Tutor a Distância: o regresso ao paradigma da sala de aula. Discursos, Perspectivas em Educação, n. 1, p.77-89, 2003.

MOTA, J. Personal Learning Environments: contributos para uma discussão do conceito. Educação, Formação \& Tecnologias, v.2, n.2, p. 5-21, 2009. Disponível em: <http://eft.educom.pt/index.php/ eft/article/view/105>. Acesso em: 01 ago. 2017.

MOORE, M. G.; KEARSLEY, G. Educação a distância: uma visão integrada. São Paulo: Cengage Learning, 2008. 398 p.

NÓVOA, A. L'Europe et l'éducation : analyse socio-historique des politiques éducatives euripéennes. In NÓVOA, A. Histoire \& Comparaison: essais sur l'Éducation. Lisboa: Educa, 1998. p.85-119.

OKADA, A. Introdução sobre o conceito Coletividade. Colearn. 2011. (Grupo de pesquisa on-line). Disponível em: <http://openscout. kmi.open.ac.uk/tool-library/ >. Acesso em: 12 jun. 2017.

OKADA, A. et al. Knowledge media tools to foster social learning. In: HATZIPANAGOS,S.; WARBURTON, S. (Ed.). Handbook of research on Social Software and developing Community Ontologies.

Hershey PA: IGI Global, 2009.p.10-20. DOI: ttps://doi.

org/10.4018/978-1-60566-208-4.ch024

PAWLOWSKI, J. et al. OpenScout OER \& Adaptation Handbook. 2012. Disponível em:<http://learn.openscout.net/ resource.html?loid=OpenScout:6a73c645-0244-11e2-8c2fc37fb8292160>. Acesso em: 02 ago. 2017.
PEREIRA, A. et al. Contributos para uma Pedagogia do Ensino Online Pós-Graduado: Proposta de um Modelo. Discursos, Perspectivas em Educação, n.1, p.39-51, 2003.

PEREIRA, A. et al. Um Modelo Pedagógico Para o Ensino Graduado Online. In: COLÓQUIO LUSO-BRASILEIRO DE EDUCAÇÃO A DISTÂNCIA E AMBIENTES VIRTUAIS DE APRENDIZAGEM, 1., 2006, Salvador. Apresentação. Salvador : UNEB, 2006. Disponível em:< https://pt.slideshare. net/AnaPaiva2011/pereira-a-et-al-um-modelo-pedaggico-para-oensino-graduado-online-egrad>. Acesso em: 30 jul. 2017.

PEREIRA, A. et al. Modelo Pedagógico Virtual da Universidade Aberta: para uma universidade do futuro.Lisboa: Universidade Aberta, 2007. 112 p.

PESTANA, F. A Wikipédia como Recurso Educacional Aberto: conceçốes e práticas de estudantes e professores no ensino superior online. 2014. Dissertação (Mestrado em Pedagogia do E-Learning) - Universidade Aberta, Lisboa, 2014. Disponível em: <http:// repositorioaberto.uab.pt/handle/10400.2/3370 >. Acesso em: 27 jul. 2017.

QUINTAS-MENDES, A,; GRAVE, L. L'Enseignment à Distance et en Ligne au Portugal. L'Experience de l'Universidade Aberta. In: GUILLARD, C.; VAUTHIER, J. (Ed.). Towards a Virtual Erasmus, Heal, Edu-Learn. Paris: [s.n.], 2004.

QUINTAS-MENDES, A.; CRATO, R. Formação de E-Formadores: alguns princípios pedagógicos . Discursos, Série Perspectivas em Educação, n. 2, p.171-176, 2004.

RUMBLE, G. 'Open learning', 'distance learning', and the misuse of language. Open Learning: the Journal of Open, Distance and e-Learning, v.4, n.2, p.28-36, 1989.

SCHAFFERT, S.; HILZENSAUER, W. On the Way towards Personal Learning Environments: Seven Crucial Aspects. eLearning Papers. n. 9, p.1-11, 2008. Disponível em: <http://citeseerx.ist.psu. edu/viewdoc/download?doi=10.1.1.167.4083\&rep=rep1\&type=pdf >. Acesso em: 30 jun. 2017.

SELWYN, N. Education and Technology: key issues and debates. London: Continuum International Publishing Group, 2011. p.197.

SOUZA, SPILKER, M.J.; AMANTE, L. Literacia Digital: O módulo de Ambientação Online na Universidade Aberta. In: M.J. Gomes; A. Osório; A. Ramos; L. Valente (Org.). Atas da IX Conferência Internacional de TIC na Educação. Challenges 2015. Braga: Centro de Competência TIC do Instituto de Educação da Universidade do Minho, 2015. p.924-93. Disponível em: <https:// www.nonio.uminho.pt/challenges2015/?page_id=496 >. Acesso em: 31 jul. 2017.

TEIXEIRA, A. Uma nova ideia de Universidade (Prefácio). In: PEREIRA, A. et al. Modelo Pedagógico Virtual da Universidade Aberta: para uma universidade do futuro. Lisboa: Universidade Aberta, 2007. p.4-5.

TUOMI, I. Open Educational Resources and the Transformation of Education. European Journal of Education, v.48, n.1, p. 58-78, 2013. 
UNESCO. Declaração de Paris sobre Recursos Educacionais Abertos. In: CONGRESSO MUNDIAL SOBRE RECURSOS EDUCACIONAIS ABERTOS- REA, 2012, Paris. Apresentação. Paris, 2012. Disponível em: <http://www.unesco.org/fileadmin/ MULTIMEDIA/HQ/CI/CI/pdf/Events/Portuguese_Paris_OER_ Declaration.pdf >. Acesso em: 01 ago. 2017.

WEINBREN, D. The Open University: a history. Manchester: Manchester University Press, 2015. 416 p.

WELLER, M. Reflections on openness. The Ed Techie, 2009. Disponível em:< http://nogoodreason.typepad.co.uk/no_good_ reason/2009/09/reflections-on-openness.html>. Acesso em: 2 ago. 2017.

. The openness-creativity cycle in education. Journal of Interactive Media in Education 2012, v.1, n.2. DOI: http://dx.doi. org/10.5334/2012-02 